\title{
Proposta de quadro de transferência automático de baixo custo para Instalações Elétricas de pequeno porte
}

\author{
Automatic Transfer Switching Proposal for Small Electrical Installations
}

Matheus Leal Silva ${ }^{{ }^{*}}$, Carlos Jesivan Marques Albuquerque ${ }^{\ddagger}$, José Augusto de Lima Texeira Júnior*, José Antônio Bento de Andrade $\$$, Janaina Lavinas Moura

Como citar esse artigo. Silva, ML; Albuquerque, CJM; Texeitas Junior, JAL; de Andrade, JAB; Moura, JL; Fortes, MZ. Proposta de quadro de transferência automático de baixo custo para Instalações Elétricas de pequeno porte. Revista Teccen. 2018 Jan/Jun.; $11 \quad$ (1): 26-38.

\begin{abstract}
Resumo
Disponibilizar geradores como fonte adicional de energia elétrica para instalações elétricas comerciais e industriais, em paralelo ou independente da rede da concessionária, é um procedimento comum, e tem por finalidade prover energia a partir de fonte secundária, pela alternância total com a rede comercial. A prática visa redução de custos tarifários em horário de ponta e composição de sistema emergencial de fornecimento de energia em caso de interrupção da concessionária, evitando-se efeitos de paradas em processos críticos. Nessas instalações, por envolverem demandas elevadas de potência, Quadro de Transferência Automático (QTA) é em geral empregado, para a comutação entre as fontes, constatando-se alta viabilidade técnica e econômica. Em instalações elétricas de baixa demanda, como as residenciais, geradores com potências nominais da ordem de 4 a 15 kVA são empregados, e o uso de um QTA não é comum, principalmente por questões econômicas. Por aspectos construtivos, boa parte dessas máquinas, embora com partida elétrica, não são totalmente automatizadas. QTA's comerciais podem ser adaptados, mas os custos não são, em geral, compensadores. Este trabalho abordatal questão, e versa sobre um QTA em proveito de instalações de baixa demanda. Propõe o desenvolvimento de um sistema de baixo custo, com base em microcontrolador de plataforma aberta e princípio de atuação e funcionalidades similares às existentes em produtos comercialmente disponíveis para geradores de potência inferior a $15 \mathrm{kVA}$. O hardware proposto, além da placa eletrônica de controle, conta com Relés de Interface, Relés Falta de Fase e Contatores Magnéticos, sendo as funções integradas a um display indicador de estados. O trabalho realizado envolveu ações que abrangeram desde os estudos iniciais para concepção, dimensionamento e especificações de componentes eletroeletrônicos, até o desenvolvimento de protocolos de monitoramento e acionamento, bem como toda a programação da plataforma na linguagem pertinente.O sistema modular, potencialmente vantajoso para o projeto, foi concebido com base em dois principais módulos: de comando e de potência, o que permite ajustes técnicos com mais eficiência e facilidade na análise. Permitir adequação a situações diversas representa também vantagem dessa modularidade.

Palavras-Chave: Demanda em Instalações Elétricas; Transferência Automática; Microcontrolador de Plataforma aberta.
\end{abstract}

\begin{abstract}
Providing commercial and industrial installations with generators as a secondary source of energy, both in parallel and independent, is something usual and it is made in order to do not let the load without any source of energy when there is an absence of local power concessionary. It has, as the main goal, reducing costs in bills at the rush time and composing an emergency energy system, avoiding critical losses in the process. These kinds of installationsrequire great demands for energy and, for those cases, Automatic Transfer Switching (ATS)is applied, as usual, to alternate the primary and secondary sources of energy, and the technical and economic viability are noticed. In smaller installations, as houses, is used generators with a value of power between 4 and $15 \mathrm{Kva}$, but Automatic Transfer Switching does not, mainly for economic issues. Most of these machines have electrical starting, however, they are not completely automatic, and it's necessary adaptations to well use of the ATS that it's not, in general, economically viable. This working paper deals with that issue, and make a purpose of a low-cost ATS for smaller installations based on the microcontroller in open source platform and mechanisms that are present in commercial products for generators until $15 \mathrm{kVA}$. The hardware exposed, besides the microcontroller, is composed of Interface Relays, Faut Phase Relays, Display, and Magnetic Contactors. The purpose involved since initial studies, for conception and specifications of electric and electronic components, until development, via software, of code protocols for starting, monitoring and switching of the process. Modular system, with a potential advantage for the project, was conceived in two main modules: Control and Power modules, what allows technical adjusts efficiently.

Keywords: Demand for Energy; Automatic Transfer; Open Source Platform.
\end{abstract}

\section{Introdução}

A instalação de um gerador ou grupo de geradores, para uso em instalações elétricas comerciais e industriais com demandas elevadas, tem como funções principais a mitigação de custos tarifários em horário de ponta, por exemplo, e permitir o fornecimento de energia em caso de interrupção da concessionária - reduzindo efeitos de paradas em processos críticos. Tais funções

Afiliação dos autores: $\uparrow$ Universidade de Vaasouras, Egresso, Vassouras - RJ, Brasil.

\$ Universidade de Vassouras, Docente, Vassouras - RJ, Brasil

*Email para correspondência: leal.silva1992@gmail.com 
são proporcionadas pela possibilidade de alternância total entre as fontes de energia, da concessionária e do gerador.

Denomina-se Quadro de Transferência Automático (QTA) um painel elétrico de controle que pode ser utilizado sobre geradores de energia, para acionar a partida desses equipamentos na falta da energia da concessionária ou em casos que sejam devidamente programados para este fim. O hardware de um QTA em geral inclui placa eletrônica de controle e dispositivos elétricos e eletromagnéticos funcionais, como relés de Interface, de falta de fase e contatores magnéticos. É um dos dispositivos mais importantes em um gerador, ao controlar e executar ações diversas para o fornecimento de energia por meio do gerador. Pode ser programado para desempenhar funções essenciais, como a comutação imediata ou a interrupção do fornecimento da rede externa. É comum também, caso ocorra falha que impeça o acionamento, a existência de mecanismo que realiza bloqueio para manter a integridade do gerador de energia, permitindo a partida manual. Seu é essencial em situações em variados segmentos de atividade onde falta de continuidade no fornecimento de energia acarreta grandes prejuízos; como exemplos, o agropecuário e o controle de tráfego aéreo, passando por indústrias de grande porte. Sua instalação no gerador também é essencial durante a realização de grandes eventos.

Em instalações comerciais e industriais, em que maiores demandas de potência estão envolvidas, é em geral viável técnica e economicamenteo uso do QTA na comutação entre fontes.Em instalações de baixa demanda, como residenciais, onde se usam geradores de potências da ordem de 4 a $15 \mathrm{kVA}$, embora em geral possuam recursos para serem acionados a partir de QTA, adaptados ou fornecidos pelos fabricantes, os custos, não são compensadores, não sendo comum seu uso.

O presente artigo propõe o desenvolvimento de um protótipo de QTA em proveito de instalações de baixa demanda, de baixo custo, com base em microcontrolador de plataforma aberta e princípio de atuação e funcionalidades similares às existentes em produtos comercialmente disponíveis, para geradores movidos a gasolina, de potência inferior a $15 \mathrm{kVA}$. O hardware proposto inclui a placa eletrônica de controle, na adequada programação, e demais dispositivos elétricos e eletromagnéticos pertinentes. Todas as funções são integradas a display indicador de estados. Sistema modular foi concebido, vantajoso para o projeto, por permitir ajustes técnicos com mais eficiência e facilidade na análise e correção de defeitos.

\section{Transferência entre fontes de energia}

Chaves de transferência ou reversoras, segundo
Asano (2015), têm como função a seleção entre uma fonte principal de energia elétrica e outra alternativa.

As chaves reversoras possuem diversas formas construtivas, desde chaves eletromecânicas, até comutadores de estado sólido baseadas em componentes eletrônicos, podendo a transferência ser do tipo aberta ou fechada. A transferência fechada é a forma mais comum e menos "burocrática" de se realizar transferência entre fontes de energia. Sua ação baseia-se em retirar a alimentação oriunda da concessionáriae, após intervalo de tempo predeterminado em stand by, fazer a comutação para a fonte de energia secundária (Pereira, 2009). Conforme Asano (2015), por não requerer paralelismo - operação simultânea das fontes de energia, seu emprego não obriga apresentação de documentação específica à concessionária de energia para operar normalmente esse chaveamento na instalação elétrica. Este tipo de transferência é ideal para sistemas de geração em circuitos de emergência e fornecimento em horário de ponta. A figura 1 mostra esquematicamente uma chave de transferência aberta. A fonte de energia da concessionária é representada pela ligação trifásica do transformador e pela linha secundária que, na prática, é a rede de baixa tensão que alimentará a carga. A chave de transferência fará a seleção entre essa rede de distribuição e o gerador.Ainda de acordo com Pereira (2009), todas as concessionárias de energia elétrica exigem o intertravamento mecânico,e se possível, o intertravamento elétrico, das chaves reversoras quando se trata de transferência aberta.

A transferência fechada tem seu mecanismo de ação baseado em um paralelismo momentâneo entre a rede da concessionária e o gerador e requer aprovação por parte da concessionária, com atendimento a requisitos técnicos. A transferência fechada requer um sistema de controle para o sincronismo do gerador com a rede (Asano, 2015). De acordo com Pereira (2009), o sistema de controle deve monitorar o fluxo de corrente e o nível de combustível do gerador para que o mesmo não seja comutado a plena carga nem que seja motorizado pela rede elétrica, devendo haver um acoplamento gradativo de potência da carga ao gerador, a uma taxa de variação constante - acoplamento em rampa. Na figura 2 , mostrando a transferência fechada, o sincronismo é feito a partir do sistema controle em malha fechada, onde os Transformadores de corrente (TC's) monitoram a tensão gerada pelo gerador (variável de saída, ou controlada), ajustando a excitação do campo e a injeção de combustível da máquina (variáveis manipuladas). Quando é estabelecido o sincronismo do gerador com a rede da concessionária, o disjuntor $52 \mathrm{U}$ é comutado, acoplando gradativamente a carga com o gerador. Quando a transferência for completada, abrir-se-á a chave geral. 


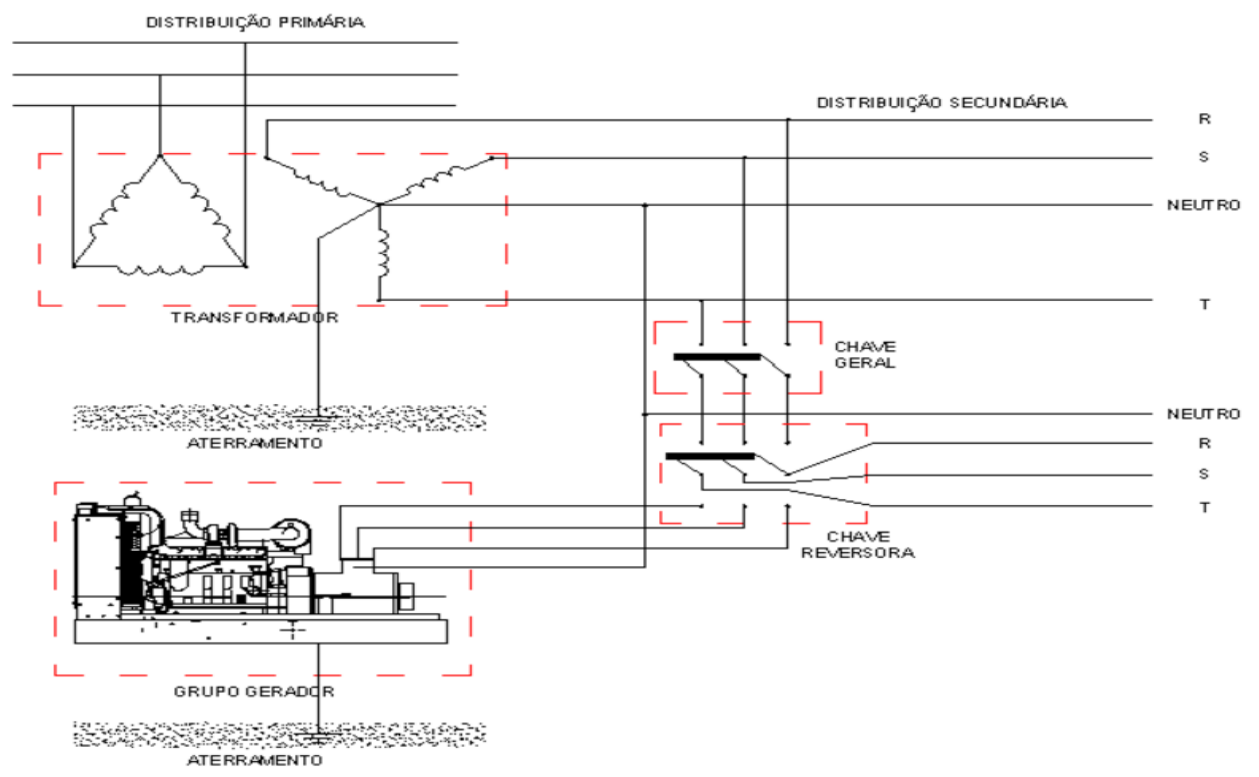

Figura 1. Esquema básico de chave transferência aberta. Fonte: Pereira (2009)

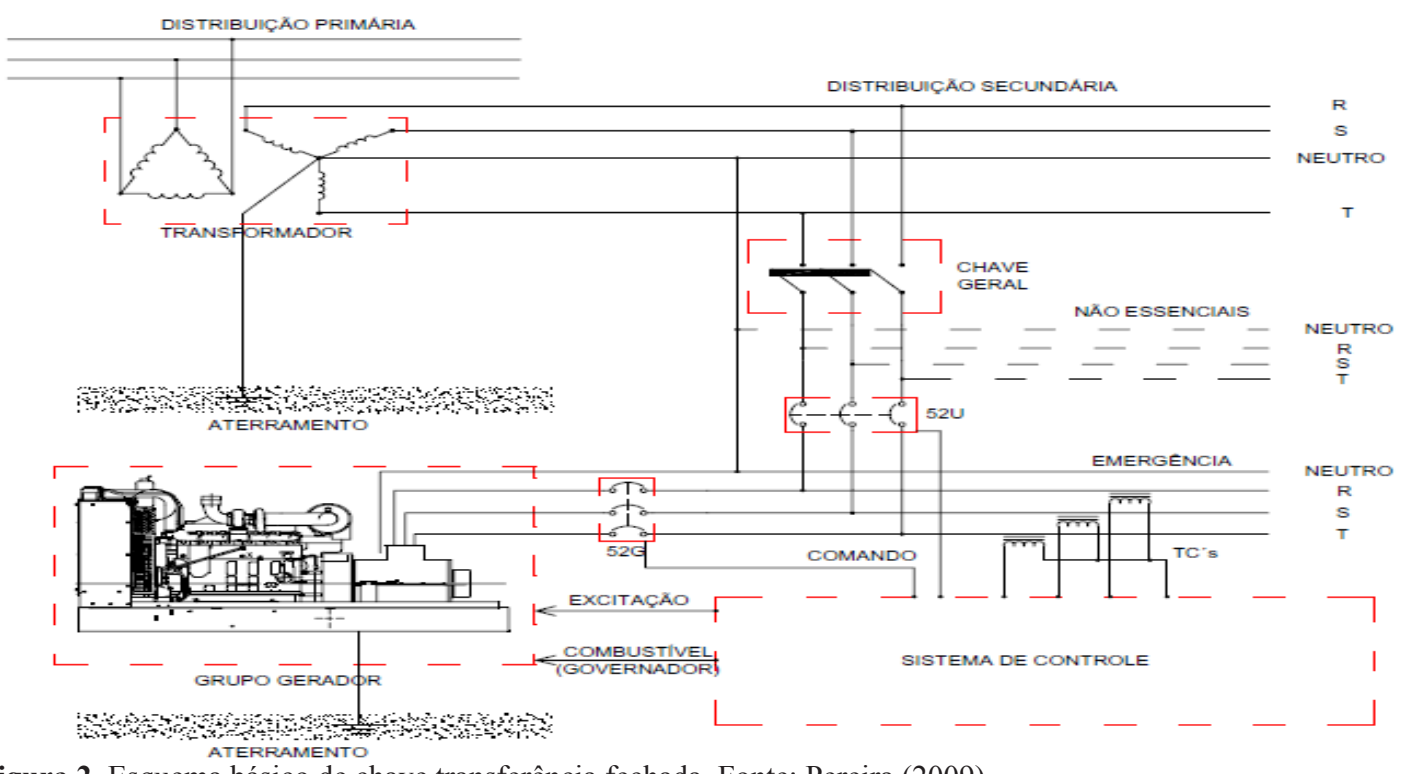

Figura 2. Esquema básico de chave transferência fechada. Fonte: Pereira (2009)

\section{Instalação definida como referência}

Definiu-se residência padrão como referência de instalação elétrica de baixa demanda, com características como se seguem, tomadas como base:

- Área útil da residência de $81,41 \mathrm{~m}^{2}$, com 02 (dois) quartos, 01 (um) banheiro, 01 (uma) cozinha, 01 (uma) sala de estar, 01 (uma) área de serviço, 01 (uma) garagem e 02 (dois) cômodos dedicados a máquinas e ferramental.

- Circuitos elétricos, em um total de dez, resumidos e especificados no quadro 1, projetados e organizados segundo os padrões exigidos pela NBR 5410.
Quadro 1: Circuitos elétrico da Instalação Residencial.

O gerador da residência localiza- se nos fundos, e o Quadro Geral de Distribuição, na cozinha. O fornecimento da concessionária é feito via aérea até o padrão de medição e subterrâneo até o Quadro de Disjuntores. Parâmetros de entrada:

a. Carga Instalada Prevista: 16,9 kVA;

b. Demanda Individual: 13,2 kVA;

c. Proteção Geral: Disjuntor Tripolar de 40A;

d. Condutores de entrada: 3 condutores fase e 1 condutor neutro de $10 \mathrm{~mm}^{2}$;

e. Aterramento: 1 Condutor de $10 \mathrm{~mm}^{2}$;

f. Potência nominal do gerador de emergência: 


\section{$11,5 \mathrm{kVA}$;}

A figura 3 mostra a fachada da residência, com a posição definida do padrão de medição e proteção da concessionária.

Quadro 1. Circuitos elétrico da Instalação Residencial.

\begin{tabular}{|c|c|c|}
\hline Circuito & Descrição & $\begin{array}{l}\text { Potência } \\
\text { (VA) }\end{array}$ \\
\hline 1 & $\begin{array}{l}\text { Iluminação- Sala; Quartos; Circulação; } \\
\text { Garagem; Varanda, Área Externa. }\end{array}$ & 1140 \\
\hline 2 & $\begin{array}{c}\text { Iluminação- Cozinha; Área de Serviço; } \\
\text { Banheiro; Lavabo; Depósito. }\end{array}$ & 560 \\
\hline 3 & $\begin{array}{l}\text { Tomadas de Uso Gera1- Sala; Quartos; } \\
\text { Circulação; Garagem; Varanda. }\end{array}$ & 1900 \\
\hline 4 & Tomadas de Uso Gera1- Cozinha & 2100 \\
\hline 5 & $\begin{array}{c}\text { Tomadas de Uso Geral- Área de Serviço e } \\
\text { banheiro }\end{array}$ & 2400 \\
\hline 6 & Ar Condicionado 12000 Btu- Quarto 1 & 1600 \\
\hline 7 & Microondas. & 1500 \\
\hline 8 & Chuveiro & 5500 \\
\hline
\end{tabular}

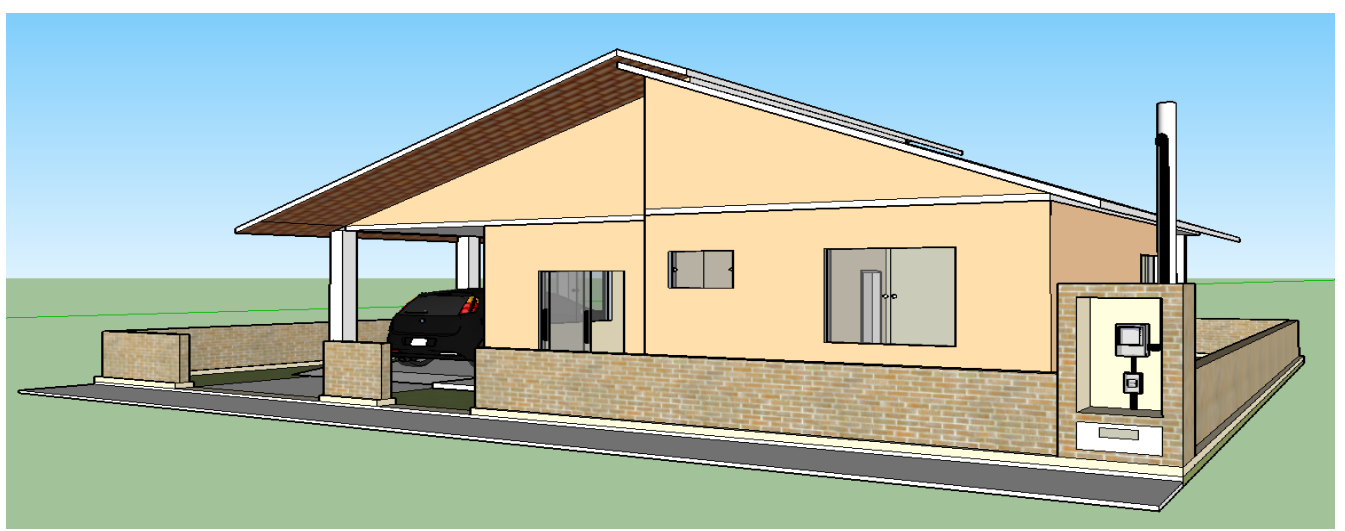

Figura 3. Maquete Eletrônica da Residência. Fonte: os autores (2017)

\section{Conceito e Características gerais da proposta de QTA}

Deseja-se inserir na instalação elétrica sistema de acionamento automático (Transferência Automática) para o gerador a gasolina nas condições que se seguem:

a. Em caso de falta:há tempo de espera para religamento da concessionária, sendo o gerador acionado somente após este tempo.

b. O gerador será desligado automaticamente após o retorno do fornecimento da concessionária;

c. $\mathrm{O}$ fornecimento de energia do gerador e da rede elétrica nunca poderão ser simultâneos na instalação elétrica;

d. Todos os processos envolvidos no funcionamento serão mostrados através de um Display e por sinalização luminosa;

A proposta de projeto prevê um QTA para a realização de transferência aberta, com base em sistema de controle a microcontrolador, que enviará comandos de programação específicos a todos os componentes 
envolvidos no processo.

\section{Modo de atuação do QTA e protocolos de partida do gerador}

O modo de atuação prevêque o sistema de controle fará o monitoramento contínuo do padrão de entrada a fim de verificar se há ausência de energia elétrica. Se houver, é verificado se a rede é religada em tempo preestabelecido. Constatado que houve apenas uma oscilação e a concessionária voltou a fornecer energia para a carga, o dispositivo responsável pelo chaveamento do fornecimento da rede retornará à situação original, e o gerador não será acionado. Caso contrário, será iniciado o protocolo de acionamento do gerador, que inclui a partida do motor a combustão e o acionamento do dispositivo responsável pelo fornecimento de energia a partir do gerador.

O protocolo de acionamento do geradortomou por base instruções constantes no manual de gerador a gasolina de modelo e fabricante comumente encontrado no mercado, cujo procedimento de acionamento segue a seguinte sequência: abertura da válvula de combustível; acionamento do sistema elétrico da máquina,acionamentodo motor de arranque $\mathrm{e}$ fechamento do afogador e sua consecutiva reabertura. $\mathrm{Na}$ ausência de tensão nos terminais do gerador após a partida e ainda conforme o manual utilizado para a concepção do código de programação, o protocolo de acionamento será repetido três vezes a intervalos de 10 segundos entre cada tentativa. Mantendo-se a ausência de tensão, válvula de combustível será fechada e o display acusará a falha no acionamento.

Quando do retorno da energia elétrica da concessionária, é verificada se há a oscilação da energia ou não, feita com o gerador acionado, para que não haja intervalo de alimentação inadequada da carga. Em caso de efetivo retorno da rede, dá-se o seccionamento do fornecimento do gerador e a energização de contator responsável pelo fornecimento via concessionária de energia elétrica; em seguida, o gerador é desligado.

\section{Partes componentes do QTA}

O Circuito ou módulo de Comando,responsável por enviar os comandos requisitados ao circuito de potência, é compostopor Sistema de Controle, Display, Shield de Relés e Monitoramento.

O Circuito ou módulo de Potência é constituído basicamente pelos componentes de chaveamento das fontes de energia.

A Figura 4 mostra diagrama blocos do sistema proposto e suas interligações principais. Observa-se que, a partir do Sistema de Monitoramento realimentado pelo Sistema de Potência, o Sistema de Controle irá controlar as demais partes do QTA, explicitando- se a característica cíclica de operação do processo automático previsto.

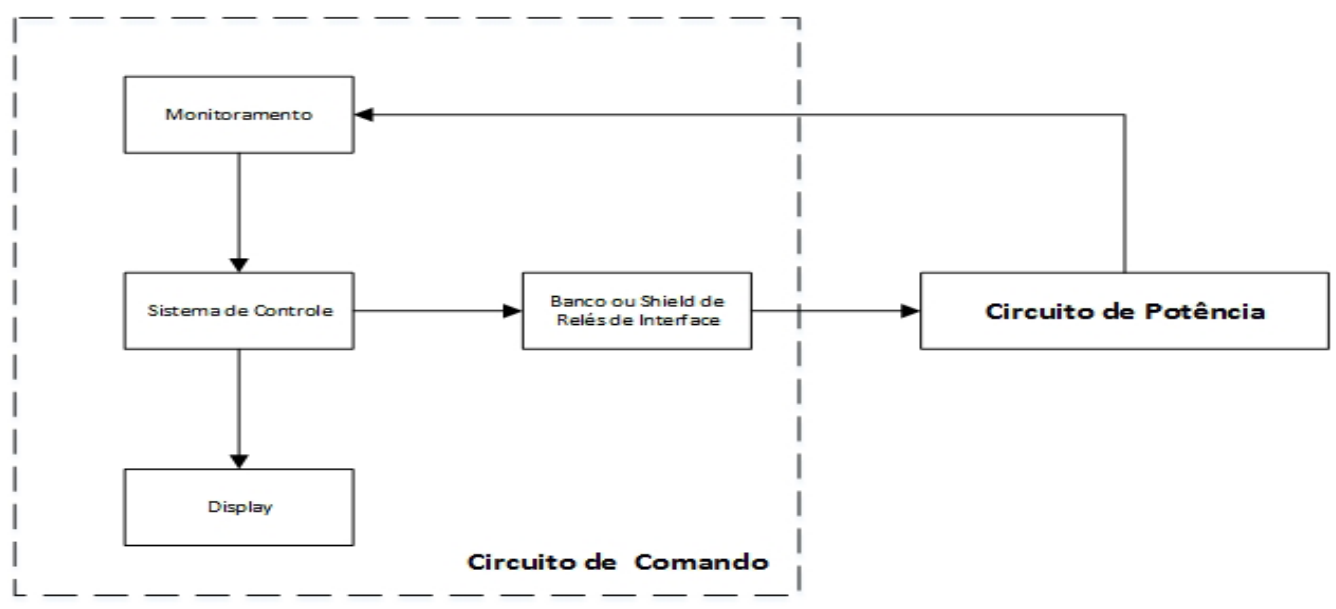

Figura 4. Diagrama em blocos funcional do QTA. Fonte: dos autores (2017) 


\section{Sistema de Controle}

Onde se processa a lógica do mecanismo de transferência entre a rede e o gerador, gerando os comandos requisitados no processo, que serão enviados ao Shield de Relés com base no monitoramento da energia do padrão de entrada e do gerador.

Com a função de fazer o processamento, é previsto o emprego de uma placa de prototipagem de plataforma Arduíno, de uso típico em sistemas embarcados, componente principal do sistema de controle. A placa é composta pelo hardware - sendo o microcontrolador o componente principal - e pelo software responsável pela programação das ações do processo.

Conforme Di Renna, Brasil,Cunha, Beppu e Fonseca(2013), o Arduino é um conjunto HardwareSoftware do tipo Open Source, ou seja, aberto ao uso e contribuição por qualquer pessoa, com propósito de ser utilizado em projetos e protótipos de baixo custo quanto ao hardware e ao software, comparado a outros sistemas existentes.

O software do Arduino pode ser usado em sistema Linux, Mac OS e Windows. Tem o $\mathrm{C}$ e o $\mathrm{C}++$ como linguagem padrão de programação do microcontrolador. Pinto, Verdelho e Santos (2012), também ressaltam que o ambiente de programação do Arduino, é uma plataforma multifunção programada em JAVA.

O hardware do Arduino emprega o microcontrolador ATMEL AVR, como componente principal, que possui microprocessador, memória e periféricos de entradas e saídas em um único encapsulamento. É inserido numa placa de circuito impresso junto ao demais componentes eletrônicos como o cristal oscilador, amplificadores operacionais, a interface USB, entre outros, afim de compor um sistema embarcado completo (Di Renna,Brasil, Cunha, Beppu e Fonseca, 2013). Contudo, Pinto, Verdelho e Santos (2012) também ressaltam que esse sistema embarcado não possui robustez e níveis de tensão adequados para operação em processos que exijam alto grau de confiabilidade, como os sistemas industriais em geral, onde um Controlador Lógico Programável é mais compatível e recomendado.

\section{Display}

LCD (Liquid Crystal Display) acoplado ao sistema de controle indicará todos os estados correspondentes aos códigos de programação do QTA, envolvidos no processo de transferência, através de mensagens textuais. O Display não é considerado uma Interface Homem-Máquina, pois não proporciona a interferência do usuário no processo, apenas o mantém informado das suas etapas (Lucena e Liesenberg, 1994).

\section{Shield de Relés de Interface}

O Sistema de Potência não pode ser conectado diretamente ao Sistema de Controle, havendo a necessidade do emprego de relés de níveis mais baixos de tensão, pertencentes ao próprio shield de relés.O Banco ou shield de Relés de Interface é onde se dá ocorre a adequação entre os níveis de tensão de controle e de potência, fazendo a intermediação entre o circuito de controle e o circuito de potência. São responsáveis pelo acionamento elétrico do gerador e pelo acionamento dos atuadores - deslocamentodo afogador do gerador e da válvula de combustível. O projeto prevê a utilização de um fototransistor para cada relé. Para acionálos, feixe proveniente da fonte emissora de radiação infravermelha, na forma de sinal digital de controle vindo do sistema microcontrolado, é direcionado para suas bases fotossensíveis, saturando-os e acionando o relé requisitado.

\section{Monitoramento}

É executado a partir dos Relés Falta de Fase. Este tipo de relé supervisiona circuitos trifásicos com defasagens de $120^{\circ}$ entre suas tensões de linha, detectando a queda de uma ou mais fases e mudando a posição do contato auxiliar. Há dois tipos de Relé Falta de Fase: com e sem neutro. O relé sem neutro faz apenas o monitoramento das fases em si no circuito, enquanto o dispositivo com neutro também monitora esse condutor (Franchi, 2008). Os diagramas das figuras 5 e 6 mostram os estados de saída,em situação de funcionamento normal e com queda de fase, para os dois tipos de relé.

No QTA proposto, é previsto o emprego de relé sem neutro, para monitorar o padrão de entrada - presença ou ausência de energia elétrica da concessionária. $\mathrm{Na}$ ausência de energia ou queda de uma ou mais fases, o sistema de controle iniciará o protocolo de teste e acionamento do gerador. Outro Relé Falta de Fase irá monitorar falhas no acionamento do gerador, acusando-a após três tentativas de partida.

\section{Circuito/módulo de Potência}

É composto por dois contatores magnéticos tripolares - alimentação da residência é trifásica responsáveis pela comutação do fornecimento de energia elétrica tanto da concessionária, quanto do gerador. A fim de aumentar a modularidade do projeto, facilitar a manutenção dos componentes e evitar eventuais interferências no sistema de controle, esse módulo do QTA será implementado em painel elétrico separado do circuito de comando. O circuito de Potência 


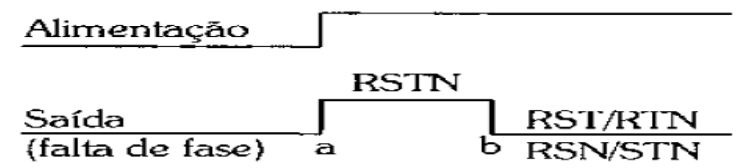

Figura 5. Diagrama Funcional do Relé Falta de Fase com Neutro. Fonte: Franchi (2008)

\section{Alimentação

\begin{tabular}{l|l|c|} 
& \multicolumn{2}{c}{ RST } \\
Saída & ST/RT/RS \\
\hline (falta de fase) & $\mathrm{b}$
\end{tabular}

Figura 6. Diagrama Funcional do Relé Falta de Fase sem Neutro.

Fonte: Franchi (2008)

usa os níveis de tensão utilizadas na instalação elétrica - $127 \mathrm{~V}$ de tensão de fase e $220 \mathrm{~V}$ de tensão de linha. Os contatores possuem intertravamento mecânico, não sendo energizados ao mesmo tempo- a Transferência a ser realizada pelo QTA é aberta. O intertravamento mecânico será complementado por estruturas específicas de comando na programação do Sistema de Controle, para garantir que os contatores nunca serão energizados simultaneamente.

\section{Layout previsto para o QTA}

O Painel de Comando acomodará a placa de prototipagem da plataforma Arduino, o shield de relés, o LCD, os componentes de entradas digitais, a chave comutadora de dois estados e os Relés Falta de Fase. Também neste painel estarão os LED's de sinalização da rede, do gerador, e o de falha de acionamento do gerador.

O Painel de Potência acomodará os componentes de força: as chaves contatoras e os disjuntores gerais. Nesse painel, os condutores do padrão de entrada e do gerador serão inseridos em eletrodutos separados.

A figura 7 mostra arranjo dos painéis do QTA. No painel de potência será também inserido um botão de emergência do tipo "Cogumelo", para o caso de

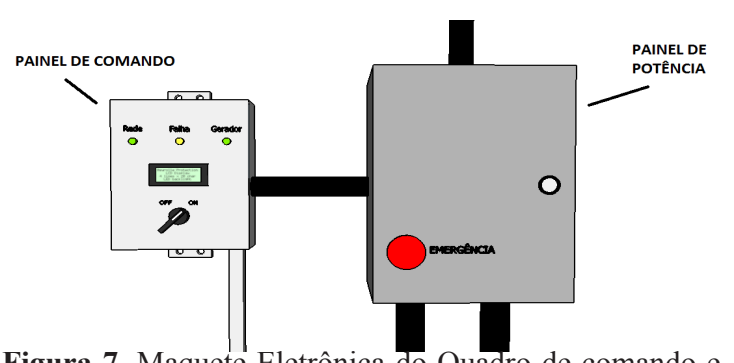

Figura 7. Maquete Eletrônica do Quadro de comando e de potência do QTA. Fonte: doa autores (2017) ocorrência de mau funcionamento do gerador ou da rede elétrica.

\section{Resultados}

Avaliação preliminar do sistema proposto foi realizada por meio de simulação via software, para visualizar as funcionalidades do processo e suas conformidades. LED's (led yellow), ao lado de cada relé, mostrados nas figuras 8, 10, 11, 12 e 13, foram usados como abstrações dos dispositivos atuadores envolvidos no acionamento do gerador e na comutação da rede elétrica. Oshield de relés de interfacefoirepresentado pelo conjunto de relés acionados a partir de circuitos a transistor, por sua vez em lugar dos fototransistores previstos para acionar os relés do shield. Foram simuladas três situações, avaliando o comportamento do QTA se. Nas figuras 8 a 13, que ilustram as simulações realizadas, o display representa uma abstração da parte física frontal do QTA, com as indicações inerentes ao processo. Os relés são numerados de 2 a 7 . O relé 1 compõe o sistema de monitoramento, não sendo apresentado nas figuras. Os terminais de saída do microprocessador são numerados de 24 a 29.

Ainda conforme as figuras acima mencionadas, o relé 2 (correspondente ao terminal 24) aciona a válvula de combustível do gerador, de bloqueio, que sempre é aberta quando o protocolo de partida se inicia, e sempre fechada quando o motor para de funcionar. O relé 3 (terminal 25) representa o acionamento do afogador, responsável pelo enriquecimento da mistura ar-combustível. O relé 4 (terminal 26), aciona o sistema elétrico do gerador. O relé 5 (terminal 27) aciona o motor de arranque da máquina primária (motor a combustão) do conjunto do gerador. Os relés 6 (terminal 28) e 7 (terminal 29) são responsáveis, respectivamente, pelo acionamento dos contatores de potência para a 
comutação do gerador e da rede elétrica.

\section{Simulação de condição normal: concessionária fornecendo energia}

Nesta situação, o gerador está desligado e a rede da concessionária não apresenta anormalidade. A figura 8 ilustra tal condição. O único relé do shield acionado nessa condição é aquele que comuta a rede da concessionária, o de número 7. O Display transcreve "REDE LIGADA" com a respectiva sinalização. Além disso, como mostrado na figura 9, ilustrando o que ocorre no circuito de potência, o gerador e o contator de potência K2 que o comuta para a carga, estarão desligados e o contator K1 está comutado para o fornecimento de energia a partir da Rede Elétrica. Observa-se ainda no diagrama à direita, na figura 9

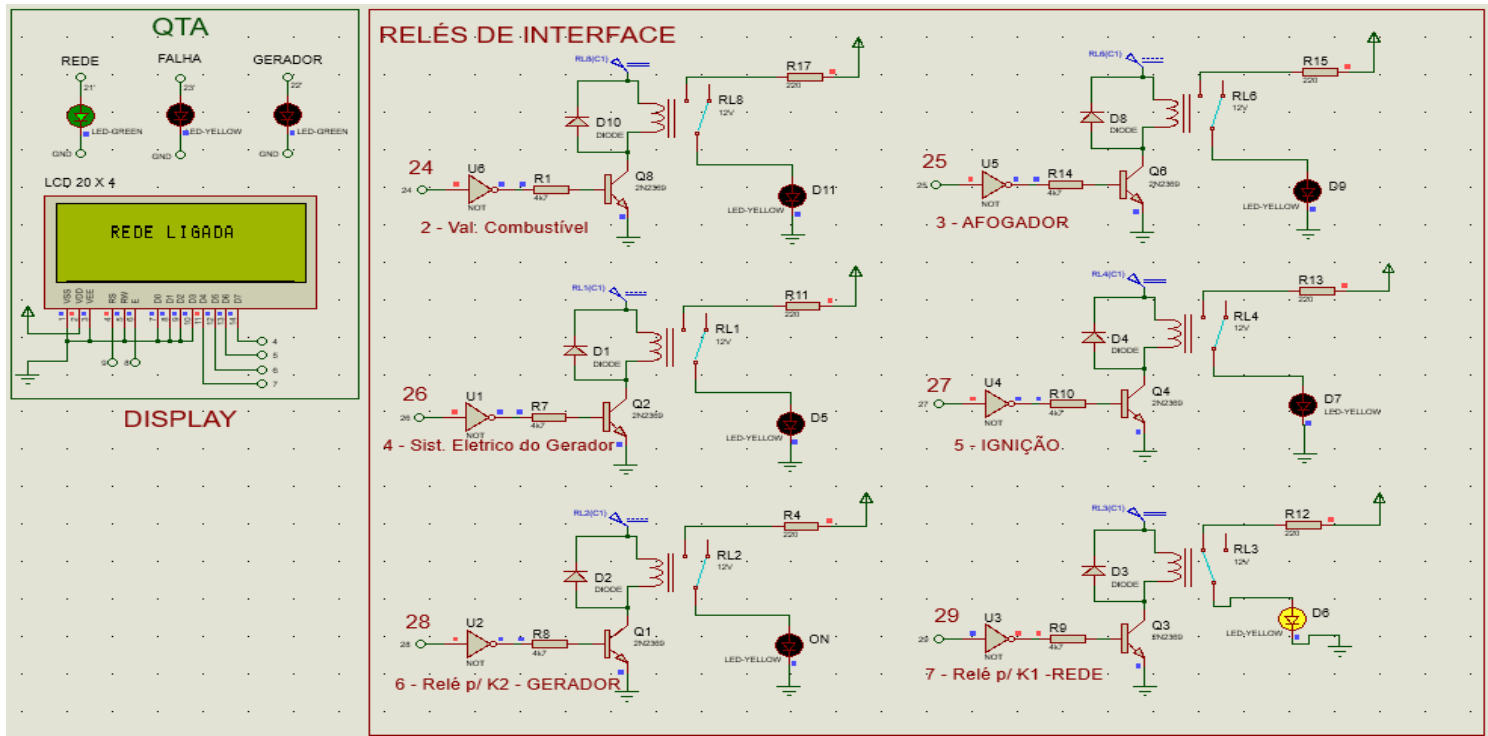

Figura 8. Sistema de Controle - Simulação da Rede Ligada. Fonte: dos autores (2017)
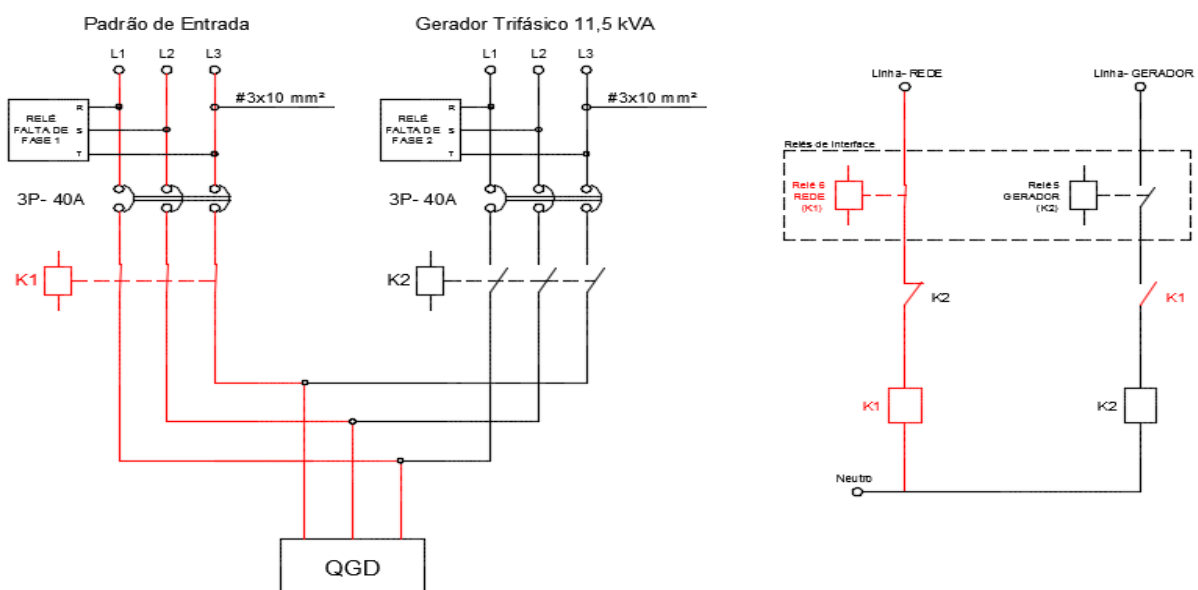

Figura 9. Circuito de Potência comutado para a Rede Elétrica. Fonte: dos autores (2017)

o intertravamento eletromecânico entre as bobinas: a bobina de K1 energizada não permite o acionamento da bobina K2 e vice-versa.

Simulação de ausência de energia na rede da concessionária e protocolo de partida do gerador: falha de Acionamento

No caso de interrupção do fornecimento da concessionária, o sistema de controle do QTA obedecerá a três protocolos distintos:

a) Teste de retorno da rede elétrica em tempo 
preestabelecido: realizado pelo sistema de controle para evitar o acionamento desnecessário do gerador se o fornecimento da concessionária se normalizar em intervalo curto de tempo;

b) Protocolo de acionamento do gerador:correspondente ao conjunto de comandos para que o gerador entre em funcionamento.

c) Comutação do fornecimento do gerador:para o fechamento dos contatos do contator de potência responsável por fornecer energia do gerador para a carga.

Se forconstatada a ausência de energia, o circuito de comando iniciará o teste de retorno normalmente. A figura 10 mostra que o relé 7 responsável por energizar o contator da Rede, estará ativo, caso o retorno da rede seja efetivado, e o fornecimento de energia para a carga se reestabeleça o mais rápido possível. $\mathrm{O}$
Display mostrará a mensagem de tal condição: "REDE EM TESTE".

Com o não retorno da energia elétrica, é iniciado o protocolo de partida do gerador, sendo acionados sequencialmente os relés $2,3,4$ e 5 , responsáveis respectivamente por: abrir a válvula de combustível, fechar o afogador, energizar o sistema elétrico da máquina primária e ligar o seu motor de arranque. O display mostra todas estas etapas do processo. Após três segundos, o relé 5 - motor de arranque, foi desenergizado, e houve o monitoramento do gerador a fim de constatar se o mesmo está fornecendo tensão nominal. Considerou-se na simulação que o monitoramento acusou falta dessa tensão do gerador, e o sistema de controle realizou os procedimentos recomendados pelo fabricante do gerador: acionar o protocolo de partida da máquina com intervalos

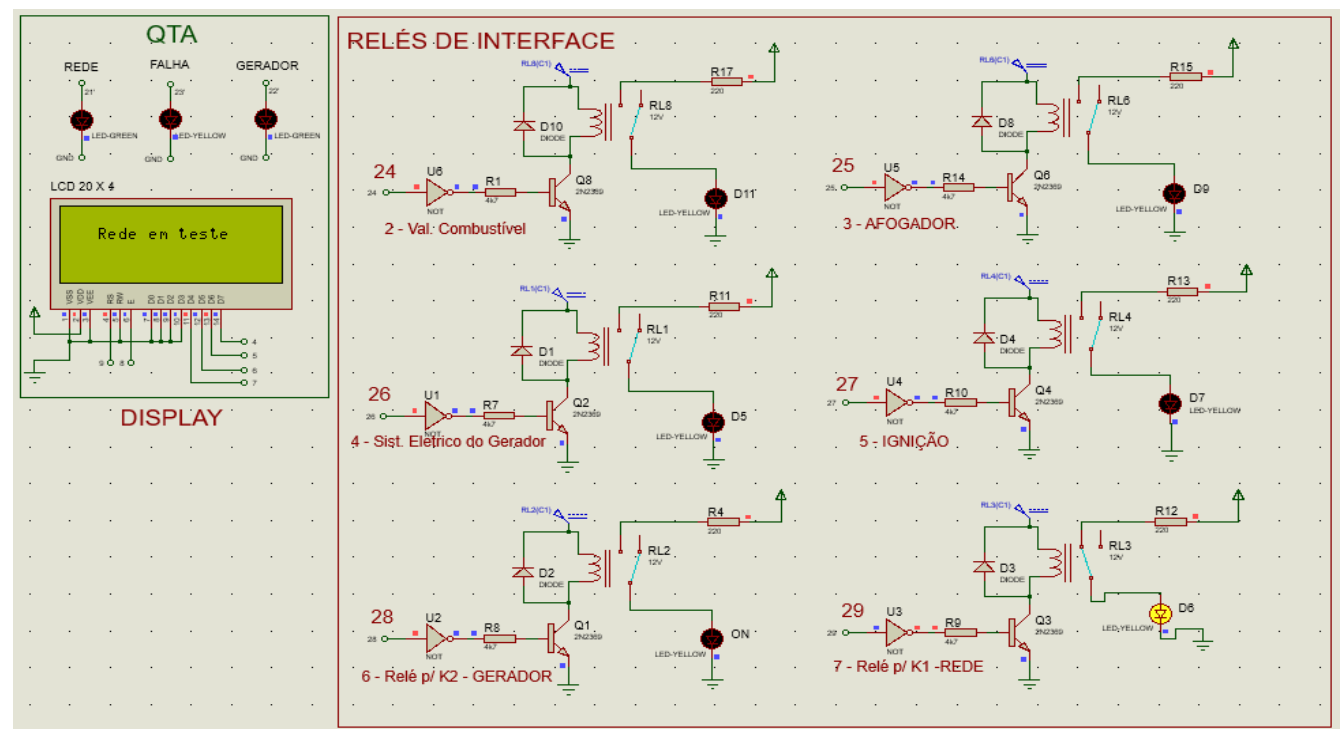

Figura 10. Simulação da Rede em Teste de Retorno. Fonte: dos autores (2017)

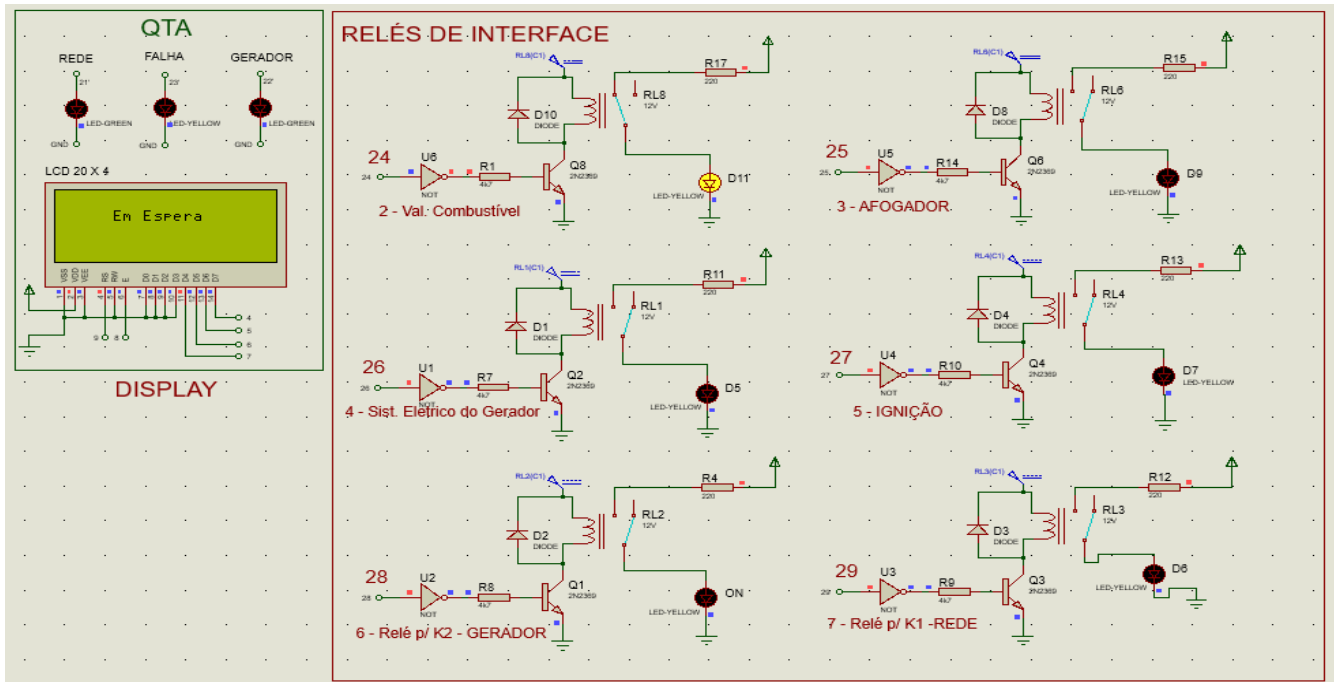

Figura 11. Circuito de Comando em Modo de Espera. Fonte: dos autores (2017) 
predefinidos de 10 segundos com no máximo três tentativas. Nesse intervalo entre as tentativas de acionamento o gerador ficou em modo de espera, sendo acusado pelo Display, conforme mostrado na figura 11.

Após as três tentativas, permaneceu a ausência de tensão nos terminais do gerador, e o sistema de controle interpretou como falha de acionamento do gerador. Com isso, todos os relés foram desenergizados e o Displaymostrou "FALHA DE ACIONAMENTO", conforme a figura 12. Em condições reais, O QTA permaneceria nessa situação até o retorno da energia elétrica, quando o sistema de controle retornaria todos os componentes para o estado da primeira simulação -contator de potência do fornecimento da concessionária energizado.

\section{Simulação de ausência de energia na rede da concessionária:gerador fornecendo energia à instalação elétrica}

As simulações anteriores foram repetidas e, após o protocolo de acionamento da máquina ser concluído, o monitoramento da tensão gerada constatoutensão na saída do gerador. ODispla ymostrou "GERADOR LIGADO", permanecendo acionados: o relé de comutação do sistema elétrico da máquina primária (relé 4), o da válvula de combustível (relé 1) e o relé

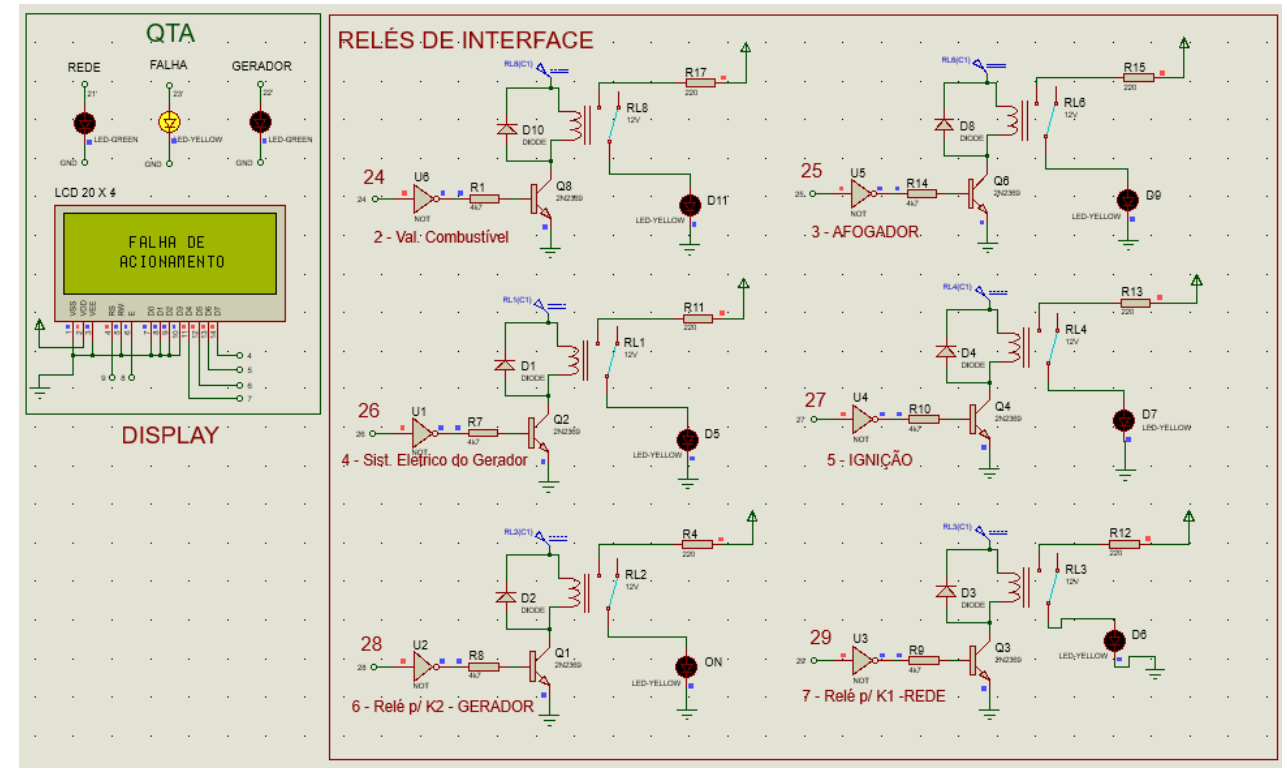

Figura 12. Falha no Acionamento do Gerador. Fonte: dos autores (2017)

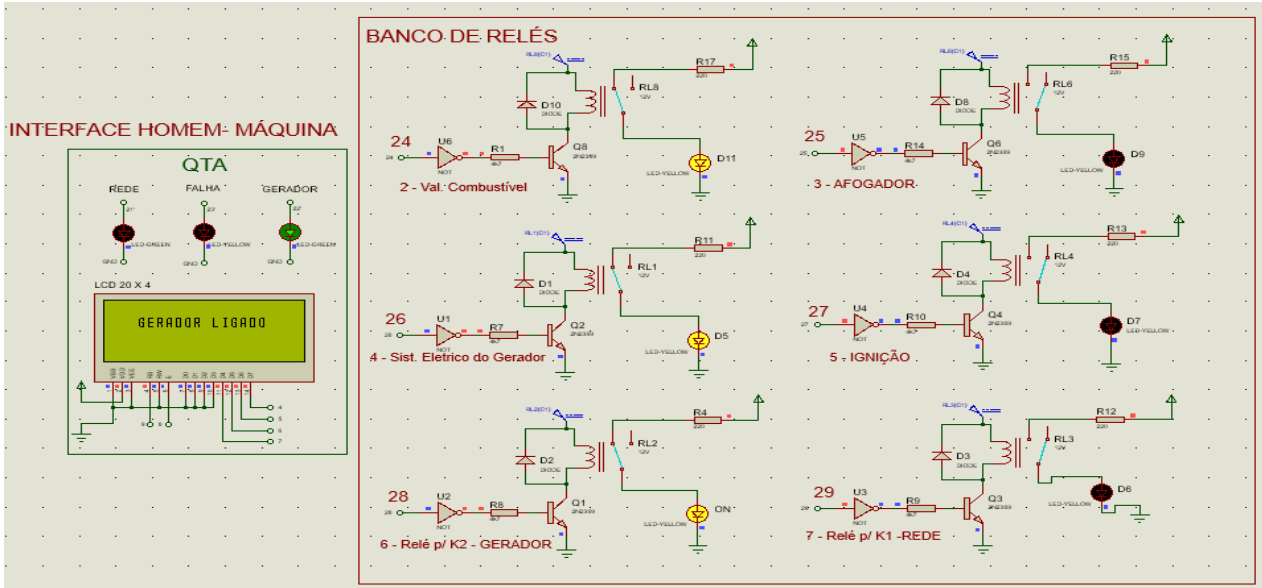

Figura 13 Simulação do Gerador Ligado. Fonte: dos autores (2017) 

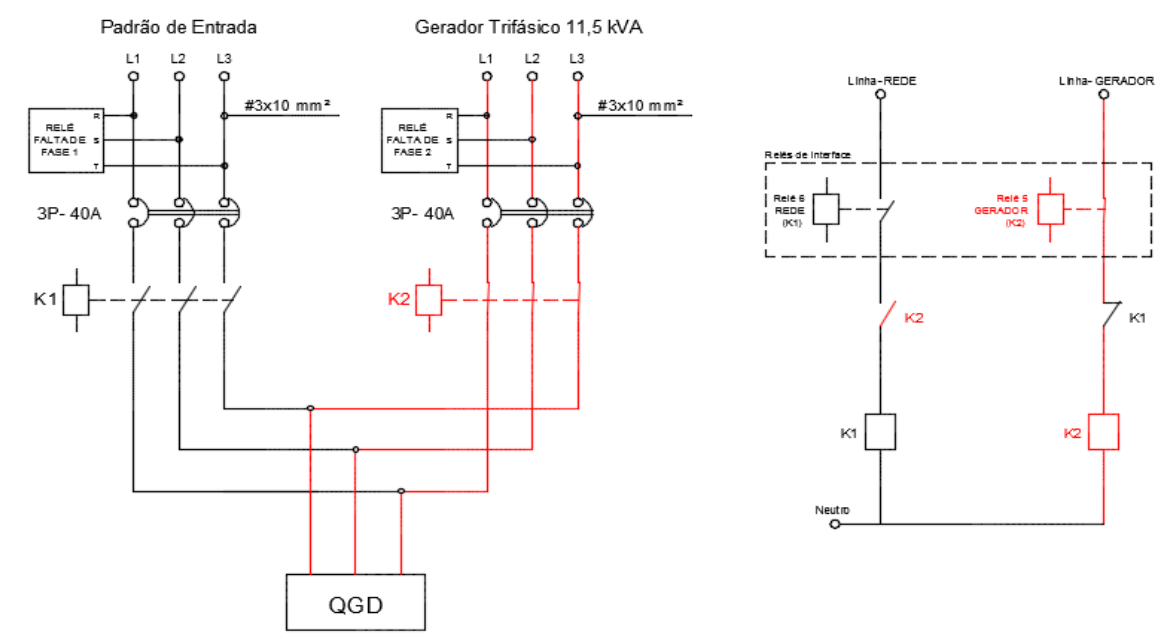

Figura 14. Sistema de Potência com Fornecimento de Energia do Gerador. Fonte: Do autor (2017)

de energização da bobina de K2 (relé 7), que comuta a energia elétrica do gerador para a residência. As figuras 13 e 14 ilustram esta simulação.

\section{Análise de resultados e discussão}

As simulações realizadas para o circuito de controle permitiram avaliar a adequação do código desenvolvido para o microcontrolador, em suas funções de monitoramento da energia elétrica do padrão de entrada e para o protocolo de acionamento do gerador, em relação a todos os aspectos e possibilidades envolvidas com esta ação, quais sejam, tentativa de acionamento com falhada máquinae tentativa com fornecimento contínuo por parte do gerador.

Todos os protocolos de espera projetados via software foram visualizados e constatou-se a integração esperada entre os componentes concebidos para o QTA. Vale ainda ressaltar que o protocolo de partida do gerador obedeceu a todos os procedimentos definidos na programação, como abertura da válvula de combustível, acionamento do afogador e tentativas de acionamento.

Todavia, percebeu-se, de acordo com o observado nas simulações realizadas, que a inserção de dois Relés Falta de Fase requer a utilização de apenas entradas digitais no microcontrolador, ou seja, a operação do sistema de controle tem seu mecanismo baseado no monitoramento de "Presença" ou "Ausência" de energia elétrica. Para distúrbios de energia elétrica como sobretensão e subtensão, entre outros, que possam causar danos à carga, o sistema poderia não ser eficaz. Tal vulnerabilidade poderia ser resolvida fazendo uso de sensores analógicos, como por exemplo, os Transformadores de Corrente (TC's).

\section{Considerações preliminares sobre custos}

A proposta de projeto como concebida, considerando os componentes dimensionados, permite visualizar custos preliminares para atender a implementação do protótipo, da ordem de valores como mostrados no Quadro 2.

Os custos preliminares envolvendo basicamente os componentes e outros materiais para a montagem do protótipo podem admitir variação da ordem de $20 \%$. É possível avaliar que o custo inicial estimado é cerca de 30 a $40 \%$ menor que o de produtos similares existentes no mercado atualmente. Todavia, o protótipo já está adaptado à situação existente da residência hipotética, com os condutores, contatores e proteções já dimensionados e adequados para o fornecimento e instalação.

\section{Outras considerações técnicas}

Diferentemente de projetos convencionais, o projeto concebido do QTA, em dois painéis distintos de potência e de comando, pode vir a aumentar o custo total do protótipo. Todavia, essa configuração apresenta, entre outras, as seguintes vantagens:

a. Maior modularidade, podendo vir a melhor viabilizar, entre outros aspectos, a execução da manutenção, corretiva e preditiva;

b. Separação bem definida dos níveis de tensão de comando e da tensão de força; e

c. Maior segurança de operação.

d. A modularidade na concepção e montagem de protótipos é também importante tendo em vista tratar-se de projeto que sofrerá mudanças até a adequação final do produto.

Em relação ao sistema de controle, é importante ressaltar que a plataforma Arduino se adequa a montagem 
Fonte: Do Autor (2017)

\begin{tabular}{|c|c|c|c|c|c|}
\hline \multicolumn{6}{|c|}{ Orçamento preliminar para um protótipo (valores referidos a Julho/2017) } \\
\hline Produto & Descrição & Qtd. & Valor Unitário & & lor Total \\
\hline Display LCD $16 \times 2$ & Display do Processo & 1 & 20,00 & RS & 20,00 \\
\hline $\begin{array}{l}\text { Placa de prototipagem } \\
\text { MEGA } 2560\end{array}$ & $\begin{array}{l}\text { Placa eletrônica da } \\
\text { plata forma arduíno }\end{array}$ & 1 & R\$ 200,00 & RS & 200,00 \\
\hline Shield com 8 Relés & Relés de $10 \mathrm{~A}$ cada & 1 & 70,00 & RS & 70,00 \\
\hline Cabos Flat & $\begin{array}{l}\text { Conexões do sistema de } \\
\text { controle }\end{array}$ & 2 & 20,00 & RS & 40,00 \\
\hline Relé Falta de Fase & $\begin{array}{l}\text { Monitoramento da Rede } \\
\text { Elétrica }\end{array}$ & 2 & R\$ 120,00 & RS & 240,00 \\
\hline $\begin{array}{l}\text { Chave comutadora de } 2 \\
\text { estados }\end{array}$ & $\begin{array}{l}\text { Seleção dos modos de } \\
\text { Operação }\end{array}$ & 1 & 20,00 & RS & 20,00 \\
\hline Botãotipo Cogumelo & botão de emergência & 1 & 15,00 & RS & 15,00 \\
\hline $\begin{array}{l}\text { Disjuntor tripolar 40A- } \\
5 \mathrm{kA}\end{array}$ & Proteções gerais & 2 & 50,00 & $\mathrm{RS}$ & 100,00 \\
\hline $\begin{array}{l}\text { Cabos condutores de } 10 \\
\mathrm{~mm}^{2}\end{array}$ & Rolo de $10 \mathrm{~m}$ & 3 & 70,00 & $\mathrm{RS}$ & 210,00 \\
\hline $\begin{array}{l}\text { Contator Magnético } \\
\text { Tripolar 40A }\end{array}$ & Chaveamento & 2 & RS 255,00 & $\mathrm{RS}$ & 510,00 \\
\hline Bateria de Lítio & Alimentação do Arduíno & 1 & 20,00 & RS & 20,00 \\
\hline $\begin{array}{l}\text { Carrega dor de Bateria de } \\
\text { Lítio } 5 \mathrm{~V}\end{array}$ & Alimentação do Arduino & 1 & 20,00 & RS & 20,00 \\
\hline Solenoide $12 \mathrm{~V}$ & $\begin{array}{l}\text { Solenoide para mecarismo } \\
\text { do a fogador e do combustível }\end{array}$ & 2 & 65,00 & RS & 130,00 \\
\hline Painel elétrico & $\begin{array}{l}\text { Quadro de comando e de } \\
\text { força }\end{array}$ & 1 & 100,00 & $\mathrm{RS}$ & 200,00 \\
\hline $\begin{array}{l}\text { Materiais Complementares } \\
\text { elogistica }\end{array}$ & Fretes etaxas & 1 & R\$ 100,00 & $\mathrm{RS}$ & 100,00 \\
\hline & & & Custo Total & RS & $1.895,00$ \\
\hline
\end{tabular}

e concepção de protótipos. Assim, o dispositivo pode não apresentar confiabilidade e imunidade, por exemplo, a ruído eletromagnético e outros fatores ambientais, como temperatura e partículas em suspensão, comum em sistemas de Transferência Automáticos homologados.

Outra consideração importante é que, para geradores recém adquiridos, se houver instalação de QTA que não seja homologado pelos fabricantes, o produto está sujeito a perda da garantia de fábrica, de acordo com normas do fabricante. Assim, o Quadro de Transferência concebido neste trabalho é adequado ao acionamento automático de geradores que estão em plena operação, mas já com a garantia expirada.

\section{Conclusão}

O presente artigo teve por objetivo apresentar os principais aspectos técnicos envolvidos com o desenvolvimento de proposta de protótipo de QTA para instalações de pequeno porte, apresentando a viabilidade técnica de tal proposta. Seu desenvolvimento visualiza a possibilidade de preenchimento de lacuna quanto a esse tipo de produto,adequado a instalações nas quais não é normalmente compensador, quando se consideram produtos comercialmente disponíveis.
Considerando uma residência padrão, como exemplar de instalação de pequeno porte quanto à demanda de potência, foram abordados os aspectos mais relevantes do hardware eletrônico envolvido, em proveito de sistema de controle de funções essenciais no processo de comutação, entre rede da concessionária e gerador.O hardware proposto tomou por base microcontrolador de plataforma aberta Arduino.

Modularidade, prevendo-se dois painéis elétricos distintos - um para o módulo de comando e outro para o módulo de potência, com baixo custo, são as características que melhor podem ser destacadas na proposta apresentada.

É possível, entretanto, observar, quando se considera em particular a adequação a ambientes que envolvam níveis realísticos de Interferência eletromagnética, condições térmicas e particulado em suspensão, bem como a abrangência de parâmetros de tensão como sobre e subtensões, leque de melhorias deve-se ter em vista. Plataformas Arduíno são indicadas para aplicações específicas de prototipagem de sistemas não críticos, que não possuem blindagens adequadas contra os agentes explicitados, que possa proporcionaradequada robustez e confiabilidade, em comparação com produtos já homologados, dotados de maior confiabilidade e garantia de fábrica. De forma 
adicional, o processo de monitoramento por meio de outros tipos de sensores, podem vir a ser bem-vindos no aperfeiçoamento da proposta.

Quanto à estimativa de custos iniciais, pode- se concluir que, apesar da oscilação de preço que pode vir a ocorrer, e levando-se em consideração que a proposta trata de um protótipo, e não de um produto de linha de produção, há potencial para que, futuramente, o Quadro de Transferência Automático descrito possa vir a ser certificado sem que haja significativo incremento no preço do produto final.

\section{Referências Bibliográficas}

Asano, A. M. (2015). Estudo de Viabilidade Técnica e Econômica da Utilização de Geração Diesel no Horário de Ponta.Trabalho de Conclusão de Curso (Graduação) Universidade Estadual Paulista - Unesp,Guaratinguetá, SP, Brasil.Recuperado em 26 de Outubro, 2016, de: $<$ http://repositorio.unesp. $\mathrm{br} / \mathrm{bitstream} /$ handle/11449/139223/000864794.pdf?sequence $=1>$.

Associação Brasileira de Normas Técnicas. NBR 5410: Instalações elétricas de baixa tensão (2 ed). (2004). RJ. Brasil.

Di Renna, R. B., Brasil, R. D. R., Cunha, T. E. B., Beppu, M. M. ,Fonseca. E. G.P . (2013). Introdução ao kit de desenvolvimento Arduino.RJ. Brasil. Recuperado em 16 de Fevereiro, 2017 de: <http://www.telecom.uff.br/pet/ petws/downloads/tutoriais/arduino/Tut_ $>$.

Franchi, C. M. (2008). Acionamentos Elétricos ( $3^{\mathrm{a}}$ ed.). São Paulo: Érica

Lucena, F. N., Liesenberg, H. K. E. (1994)Interfaces HomemComputador: Uma Primeira Introdução.Campinas. SP. Brasil

Pereira, J. C. (2009). Chaves de Transferência Automáticas -(Chaves Reversoras).

Pinto, I., Verdelho, I., Santos, T. (2012). Arduino vs PLC. Fablabedp. 